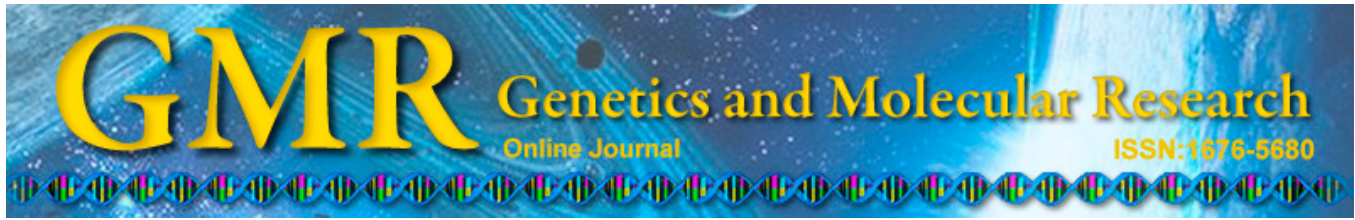

\title{
Association between polymorphisms in the adiponectin gene (APM-1) and atherosclerotic cerebral infarction in a Hainan Chinese Han population
}

\author{
P. He, X.L. Chen and Y.P. Ding \\ Emergency Center of the People's Hospital of Hainan Province, Haikou, \\ Hainan, China
}

Corresponding author: Y.P. Ding

E-mail: yipengdingcn@126.com

Genet. Mol. Res. 14 (2): 4142-4149 (2015)

Received May 19, 2014

Accepted November 10, 2014

Published April 27, 2015

DOI http://dx.doi.org/10.4238/2015.April.27.29

\begin{abstract}
We investigated the association between polymorphisms in the adiponectin gene $(A P M-1)$ and atherosclerotic cerebral infarction (ACI) in a Chinese Han population of Hainan Province. Polymerase chain reaction-restriction fragment length polymorphism and gene sequencing were used to analyze the distribution of $A P M-1+45 \mathrm{~T} / \mathrm{G}$ and $+276 \mathrm{G} / \mathrm{T}$ genotypes and their alleles in $120 \mathrm{ACI}$ patients and 120 healthy controls. No statistical correlation was found in the frequency and distribution of the genotype 45T/G between the ACI group and the control group. Genotypic frequencies of GG, GT, and TT at the $A P M-1$ +276 locus were 70.0\% (84/120), 25.0\% (30/120), and 5.0\% (6/120), respectively, in the ACI group, while these values were $52.5 \%(63 / 120)$, $37.5 \%(45 / 120)$, and $10.0 \%(12 / 120)$, respectively, in the control group. The frequency of the G allele was $82.5 \%(198 / 240)$ in the ACI group and $71.25 \%(171 / 240)$ in the control group. The $\mathrm{T}$ allele frequency was $17.5 \%(42 / 240)$ in the ACI group and $28.75 \%(69 / 240)$ in the control group. Polymorphisms at the $A P M-1-276$ locus in the case-controlled
\end{abstract}


groups showed significant differences in the genotype distribution and allele frequency between the 2 groups $(\mathrm{P}=0.041)$. The occurrence of ACI in the Hainan Chinese Han population may be associated with $+276 \mathrm{G} / \mathrm{T}$ polymorphisms but not with $+45 \mathrm{~T} / \mathrm{G}$ polymorphisms in the $A P M-1$ gene.

Key words: Adiponectin gene; Atherosclerotic cerebral infarction; Polymorphism; Single nucleotide polymorphism; Stroke

\section{INTRODUCTION}

In recent years, the age of the world population has increased. Consequently, cerebrovascular disease and other aging-related diseases have become important public health problems (Han et al., 2011). In China, the incidence rate of atherosclerotic cerebral infarction (ACI) in the ischemic stroke population is approximately $80 \%$ and is continually increasing. Therefore, an in-depth study of the pathogenesis of ACI is urgently needed. Atherosclerosis is recognized as the main pathogenesis of ACI. Adiponectin is a fat factor that is protective in the human body. Its biological effects include anti-atherosclerosis, anti-inflammation, increasing insulin sensitivity, maintaining energy balance, and involvement in glucose and lipid metabolism. Adiponectin has been shown to be an important factor influencing the susceptibility to type 2 diabetes mellitus. Polymorphisms in the adiponectin gene $A P M-1(-11377 \mathrm{C}>\mathrm{G},-11426 \mathrm{~A}>\mathrm{G},+45 \mathrm{~T}>\mathrm{G},+276 \mathrm{G} / \mathrm{T}$, $-11391 \mathrm{G}>\mathrm{A}$ ) are related to the susceptibility of type 2 diabetes (Han et al., 2011; Kacso et al., 2012; Chu et al., 2013). This may be because polymorphisms in the adiponectin gene alter adiponectin expression, which affects glucose and lipid metabolism. Atherosclerosis is caused by disorders in lipid and glucose metabolism. The anti-atherosclerosis property of adiponectin is mainly characterized by its effect on endothelial function, inflammation, and arterial remodeling (Motobayashi et al., 2009; Chen et al., 2010; Kyriazi et al., 2011).

The close correlation between adiponectin and ischemic stroke has been confirmed in numerous studies (Yatomi et al., 2009; Marousi et al., 2010; Nagasawa et al., 2011). In addition, polymorphisms in the adiponectin gene may affect adiponectin levels in the serum (Mente et al., 2013). However, no studies have examined the role of adiponectin gene polymorphisms in ischemic stroke, particularly in ACI. Some studies have found that the adiponectin gene is related to the incidence of ischemic stroke and formation of carotid artery plaques in American men, Japanese populations, and South Korean populations. However, few studies have examined these properties in Chinese populations (Hegener et al., 2006; Kim et al., 2008; Yamada et al., 2008; Cheong et al., 2011; Mente et al., 2013).

In this study, polymerase chain reaction-restriction fragment length polymorphism (PCR-RFLP) was used to investigate the distribution of 45T/G and 276G/T genotypes and alleles of $A P M-1$ in 120 ACI patients and 120 normal healthy controls. We examined the role of $A P M-1$ polymorphisms in ACI in a Han population in the Hainan Province in China, as well as provide a theoretical basis for the pathogenesis of cerebral infarction.

\section{MATERIAL AND METHODS}

\section{Subjects}

A total of 120 patients with ACI were enrolled in this study and hospitalized in the 
Department of Neurology of the People's Hospital of Hainan Province, including 78 males and 42 females with a mean age of $58.43 \pm 10.86$ years and mean body mass index of 26.28 $\pm 2.59 \mathrm{~kg} / \mathrm{m}^{2}$. All patients were diagnosed according to the revised diagnostic criteria for cerebral infarction established by the Fourth National Cerebrovascular Diseases Conference, and then confirmed by head computed tomography and/or magnetic resonance imaging. Patients with cerebral infarction caused by other diseases were excluded from this study. In addition, 120 healthy volunteers, including 60 males and 60 females with a mean age of $57.96 \pm 9.52$ years and mean body mass index of $23.10 \pm 2.14 \mathrm{~kg} / \mathrm{m}^{2}$, were enrolled as the control group in this study. Patients with stroke, coronary heart disease, kidney disease, blood disorders, autoimmune diseases, pregnancy, thrombotic disease, or having received a lipid-lowering therapy in the last 6 months were excluded from this study. All patients and the healthy controls were Hainan Chinese Han without any familial relationship. This study was conducted in accordance with the Declaration of Helsinki and with approval from the Ethics Committee of the People's Hospital of Hainan Province. Written informed consent was obtained from all participants.

\section{Preparation of DNA samples}

To prepare DNA samples, $5 \mathrm{~mL}$ sodium citrate anticoagulant peripheral venous blood was collected at 7:00 am to 8:00 am after the subjects were fasted for $12 \mathrm{~h}$. DNA was extracted from blood samples using a conventional phenol/chloroform extraction method.

\section{Primer design}

Primers were designed using the Primer Premier 5.0 software (Premier Biosoft, Palo Alto, CA, USA) and synthesized by Sangon Biotech Co., Ltd. (Shanghai, China). Gene sequencing was performed by Shanghai Biocolor Bioscience \& Technology Company (Shanghai, China). PCR primer sequences were 5'-CTGAGATGGACGGAGTCCTTT-3' and 5'-CCAAATCACTTCAGGTTGCTT-3', with a length of the amplified sequence of $456 \mathrm{bp}$.

\section{Gene sequencing}

Genotyping was performed using PCR-RFLP combined with DNA sequencing. All enzyme-digested products were separated by $2 \%$ agarose gel electrophoresis and analyzed using a GIS gel image processing system (Tanon Science and Technology Co., Ltd., Shanghai, China).

\section{Statistical analysis}

The goodness of fit of the genotypes with Hardy-Weinberg equilibrium was tested using the HWE software. Genotype and allele frequencies were calculated by direct counting. Frequency data were analyzed using the chi-square test. Measurement data in the 2 groups were compared using the Student $t$-test. Comparisons between more than 2 groups were analyzed using the analysis of variance Student-Newman-Keuls method. All statistical analyses were performed using SPSS13.0 (SPSS, Inc., Chicago, IL, USA). P $<0.05$ was considered to be statistically significant. 


\section{RESULTS}

\section{Distribution of $A P M-1+45 \mathrm{~T} / \mathrm{G}$ polymorphism}

PCR products were digested using endonuclease $E \cos 88 \mathrm{I}$ at $37^{\circ} \mathrm{C}$ for $16 \mathrm{~h}$. RFLP digestion products were separated by agarose gel electrophoresis (Figure 1). APM-1 $+45 \mathrm{~T} / \mathrm{G}$ genotype TT showed a band at $456 \mathrm{bp}$, TG showed 3 bands, 456, 313, and $1431 \mathrm{bp}$, and genotype GG showed 2 bands at 313 and $143 \mathrm{bp}$. As analyzed using the HWE software, the observed and expected numbers of the $A P M-1+45 \mathrm{~T} / \mathrm{G}$ genotypes showed no statistical differences between the ACI group and the control group $(\mathrm{P}>0.05)$, indicating that the gene frequency at the $A P M$ $1+45 \mathrm{~T} / \mathrm{G}$ locus of the population in this study was in Hardy-Weinberg equilibrium (Table 1).

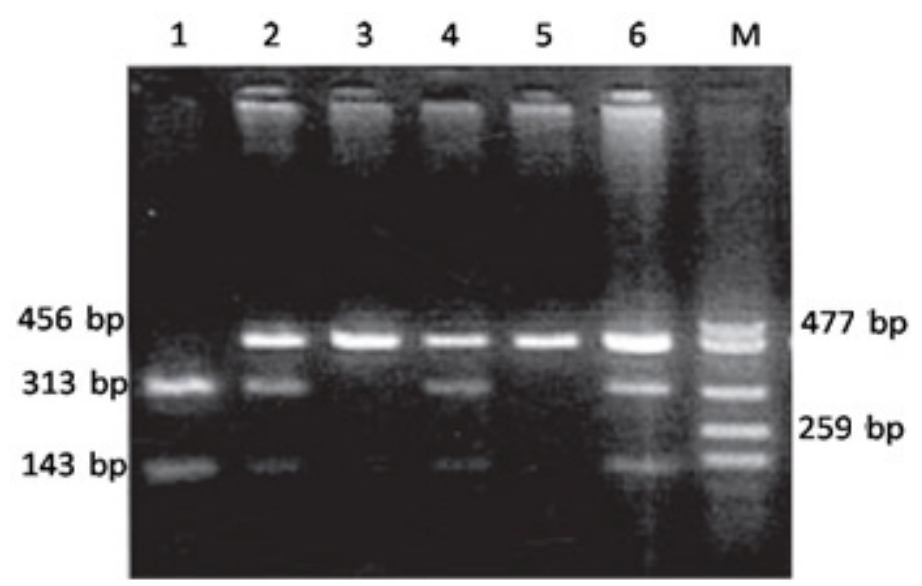

Figure 1. RFLP-PCR results of $A P M-1+45 \mathrm{~T} / \mathrm{G}$ genotypes separated by $2 \%$ agarose gel electrophoresis. Lane $M=$ DNA ladder; lane 1 = genotype GG; lanes 2, 4, 6 = genotype TG; lanes 3, 5 = genotype TT.

\begin{tabular}{llccr} 
Table 1. Hardy-Weinberg equilibrium test of $A P M-1$ & $+45 \mathrm{~T} / \mathrm{G}$ genotypes. \\
\hline & \multicolumn{4}{c}{ Genotypes } \\
\cline { 2 - 4 } & $\mathrm{T} / \mathrm{T}$ & $\mathrm{T} / \mathrm{G}$ & $\mathrm{G} / \mathrm{G}$ & Total \\
\hline Actual No. & 58 & 45 & 17 & 120 \\
Expected No. & 54.002 & 52.996 & 13.002 & 120 \\
\hline
\end{tabular}

$\mathrm{P}=0.67$.

\section{Comparison of $A P M-1+45 T / G$ genotype frequencies between the ACI group and the control group}

The frequencies of $A P M-1+45 \mathrm{~T} / \mathrm{G}$ genotypes TT, GT, and GG were $54.17 \%(65 / 120)$, $33.33 \%$ (40/120), and $12.50 \%(15 / 120)$, respectively, in the ACI group, showing no significant differences from the control group [52.50\% (63/120), 35.83\% (43/120), and 11.67\% (14/120), respectively]. Frequencies of the T and G alleles in the ACI group were 70.83 and $29.17 \%$, respectively, while these values were 70.41 and $29.59 \%$, respectively, in the control group; there was no statistically significant difference between groups $(\mathrm{P}=0.917$ for genotype frequencies, and $\mathrm{P}=0.9202$ for allele frequencies; Table 2). 
Table 2. Distribution of $A P M-1+45 \mathrm{~T} / \mathrm{G}$ genotypes and alleles $(\mathrm{N}=120)$.

\begin{tabular}{|c|c|c|c|c|c|}
\hline \multirow[t]{2}{*}{ Groups } & \multicolumn{3}{|c|}{$A P M-1+45 \mathrm{~T} / \mathrm{G}$ genotypes } & \multicolumn{2}{|c|}{ Alleles } \\
\hline & $\mathrm{T} / \mathrm{T}$ & $\mathrm{T} / \mathrm{G}$ & $\mathrm{G} / \mathrm{G}$ & $\mathrm{T}(\%)$ & $\mathrm{G}(\%)$ \\
\hline ACI group & $65(54.17 \%)$ & $40(33.33 \%)$ & $15(12.50 \%)$ & $170(70.83 \%)$ & $70(29.17 \%)$ \\
\hline Control group & $63(52.50 \%)$ & $43(35.83 \%)$ & $14(11.67 \%)$ & $169(70.41 \%)$ & $71(29.59 \%)$ \\
\hline
\end{tabular}

$\mathrm{P}=0.917$ for genotype frequencies, and $\mathrm{P}=0.9202$ for allele frequencies.

\section{Distribution of $A P M-1+276 \mathrm{G} / \mathrm{T}$ polymorphism}

APM-1 +276G/T genotypes were obtained by enzyme digestion using BsmI and separation by agarose gel electrophoresis (Figure 2). Genotype TT appeared as 1 band (456 bp), genotype TG showed 3 bands (456, 374, and $82 \mathrm{bp}$ ), and genotype GG showed 2 bands (374 and $82 \mathrm{bp}$ ). The goodness of fit test using the HWE software showed that the observed and expected numbers of $A P M-1+276 \mathrm{G} / \mathrm{T}$ genotypes in the ACI group were not significantly different from those in the control group $(\mathrm{P}>0.05)$, indicating that the gene frequency of $A P M-1$ $+276 \mathrm{G} / \mathrm{T}$ genotypes were in Hardy-Weinberg equilibrium (Table 3).

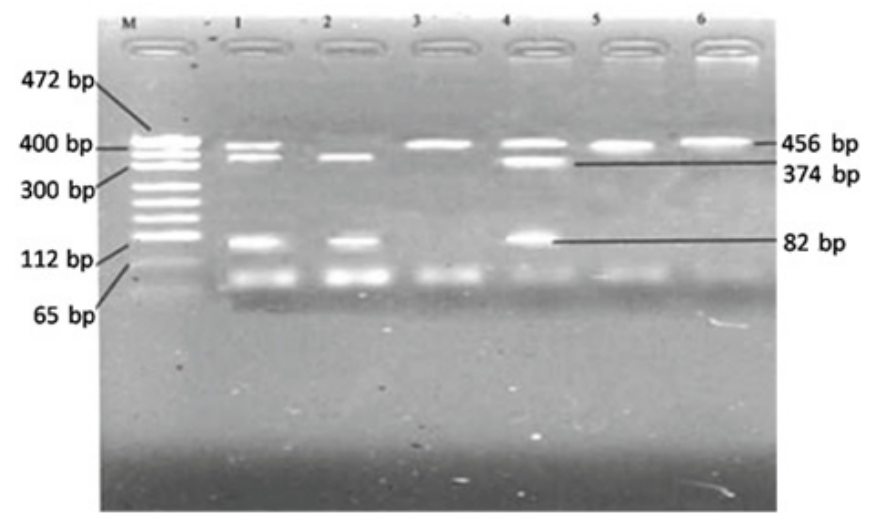

Figure 2. RFLP-PCR results of $A P M-1+276 \mathrm{G} / \mathrm{T}$ genotypes separated by $2 \%$ agarose gel electrophoresis. Lane $M$ = DNA ladder; lanes 1, 4= genotype GT; lane 2 = genotype TT; lanes 3, 5, 6= genotype GG.

Table 3. Hardy-Weinberg equilibrium test of $A P M-1+276 \mathrm{G} / \mathrm{T}$ genotypes.

\begin{tabular}{llllr}
\hline & & Genotypes & Total \\
\cline { 2 - 4 } & $\mathrm{T} / \mathrm{T}$ & $\mathrm{T} / \mathrm{G}$ & $\mathrm{G} / \mathrm{G}$ & \\
\hline Actual No. & 70 & 43 & 7 & 120 \\
Expected No. & 66.005 & 46.992 & 7.003 & 120 \\
\hline
\end{tabular}

$\mathrm{P}=0.76$.

\section{Comparison of $A P M-1+276 \mathrm{G} / \mathrm{T}$ genotype frequencies between the ACI group and the control group}

Eighty-four patients $(70.0 \%)$ carried the $A P M-1+276 \mathrm{G} / \mathrm{T}$ genotype $\mathrm{GG}, 30$ patients (25.0\%) carried the $A P M-1+276 \mathrm{G} / \mathrm{T}$ genotype GT, and 6 patients $(5.0 \%)$ carried the $A P M-1$ 
$+276 \mathrm{G} / \mathrm{T}$ genotype TT in the ACI group. In contrast, subjects with $A P M-1+276 \mathrm{G} / \mathrm{T}$ genotypes GG, GT, and TT accounted for 52.5\% (63/120), 37.5\% (45/120), and 10.0\% (12/120), respectively, in the control group. G and T allele frequencies in the ACI group was $82.5 \%(198 / 240)$ and $17.5 \%(42 / 240)$, respectively. In contrast, these values were $71.25 \%(171 / 240)$ and $28.75 \%$ (69/240), respectively, in the control group. The frequencies of the $A P M-1+276 \mathrm{G} / \mathrm{T}$ genotypes and alleles were significantly different between the ACI group and the control group (P $=0.020$ for genotype frequencies, and $\mathrm{P}=0.005$ for allele frequencies; Table 4 ).

Table 4. Distribution of $A P M-1+276 \mathrm{G} / \mathrm{T}$ genotypes and alleles $(\mathrm{N}=120)$.

\begin{tabular}{llcccc}
\hline \multirow{2}{*}{ Groups } & \multicolumn{3}{c}{$A P M-1+276 \mathrm{G} / \mathrm{T}$ genotypes } & & \multicolumn{2}{c}{ Alleles } \\
\cline { 2 - 5 } & $\mathrm{G} / \mathrm{G}$ & $\mathrm{G} / \mathrm{T}$ & $\mathrm{T} / \mathrm{T}$ & $\mathrm{G}(\%)$ & $\mathrm{T}(\%)$ \\
\hline ACI group & $84(70 \%)$ & $30(25 \%)$ & $6(5 \%)$ & $198(82.5 \%)$ & $42(17.5 \%)$ \\
Control group & $63(52.5 \%)$ & $45(37.5 \%)$ & $12(10 \%)$ & $171(71.25 \%)$ & $69(28.75 \%)$ \\
\hline
\end{tabular}

$\mathrm{P}=0.020$ for genotype frequencies and $\mathrm{P}=0.005$ for allele frequencies.

\section{DISCUSSION}

Adiponectin, identified in the mid-1990s, is a specific hormone protein secreted by adipocytes that plays an important regulatory role in glucose and lipid metabolism, insulin resistance, anti-inflammatory, anti-atherosclerosis, and other biochemical processes. Thus, it is regarded as a protective factor. Adiponectin is closely related to obesity, insulin resistance, diabetes, dyslipidemia, hypertension, coronary heart disease, and other diseases (Wasim et al., 2006; Pan and Kastin, 2007; Matsumoto et al., 2008; Rabe et al., 2008; Walsh, 2009; Ong et al., 2010).

The APM-1 gene encodes human adiponectin and is located in the chromosome $3 \mathrm{q} 27$ region. It contains 3 exons (exon 1 is a non-coding region, exons 2 and 3 contain the coding region and part of the non-coding regions for adiponectin), and 2 introns. Thirteen common single nucleotide polymorphisms (SNPs) have been identified in the APM-1 gene. These common SNPs affect type 2 diabetes mellitus, metabolic syndrome, and coronary heart disease in the chromosome 3q27 region. Therefore, the relationship between APM-1 SNPs on chromosome 3q27 and these diseases, particularly for the adiponectin 45 and 276 loci, have received increasing attention (Pischon et al., 2007; Foucan et al., 2010; Jing et al., 2012; Arnaiz-Villena et al., 2013; Lee et al., 2013).

In this study, 120 patients with ACI and 120 healthy controls were examined for the $A P M-1+45$ SNP and $A P M-1+276$ SNP variants in patients with atherosclerotic cerebral infarction in the Hainan area. The $A P M-1+45$ genotype distribution and allele frequencies in the ACI group were not significantly different from those in the control group, suggesting that $A P M-1+45 \mathrm{SNP}$ is not associated with the susceptibility to cerebral infarction, which is consistent with previous studies (Jang et al., 2005; Hegener et al., 2006). The genotype distributions at the $A P M-1+276$ locus were $\mathrm{GG}(\mathrm{N}=84), \mathrm{GT}(\mathrm{N}=30)$, and TT $(\mathrm{N}=6)$ in the ACI group and $\mathrm{GG}(\mathrm{N}=63)$, GT $(\mathrm{N}=45)$, and TT $(\mathrm{N}=12)$ in the control group. Patients with the $\mathrm{G}$ or T allele included 198 and 42 cases, respectively, in the ACI group. However, subjects with the $\mathrm{G}$ or $\mathrm{T}$ allele included 171 and 69 cases, respectively, in the control group. APM-1 +276 genotypes and alleles were significantly different between groups $(\mathrm{P}=0.041)$. Thus, the $A P M-1+276$ SNP but not the $A P M-1+45$ SNP in the $A P M-1$ gene may be correlated with the incidence of ACI. It have been confirmed that the adiponectin SNP 276G/T genotype is an 
independent risk factor for stroke and can increase the incidence of stroke (Kawai et al., 2013).

In this study, only the +45 and +276 polymorphic loci were analyzed to examine the potential relationship between variants and ACI incidence. Previous studies have examined the correlation between other loci in the $A P M-1$ gene and stroke (Liu et al., 2011). Our future studies will examine the correlation between other loci in the $A P M-1$ gene and stroke, blood pressure, and blood lipids to determine the role and mechanism of the $A P M-1$ gene in regulating blood pressure and lipids in patients with ACI. A large number of epidemiological and experimental studies found that manifestations of genetic characteristics are more obvious in ACI; in addition to environmental factors, genetic factors may play an important role. We found that some loci in the adiponectin gene were associated with ACI, but whether the adiponectin gene is a susceptibility gene for ACI requires further investigation. Therefore, the cloning and identification of the susceptibility gene and locus of ACI can clarify the genetic nature of ACI. This will be useful for detailed clinical classification of ACI, personalized treatment, and prognosis in an early stage, as well as for early screening, prevention, and treatment in individuals carrying the susceptibility gene.

\section{ACKNOWLEDGMENTS}

(\#2008-30858).

\section{REFERENCES}

Arnaiz-Villena A, Fernández-Honrado M, Rey D, Enríquez-de-Salamanca M, et al. (2013). Amerindians show association to obesity with adiponectin gene SNP45 and SNP276: population genetics of a food intake control and "thrifty" gene. Mol. Biol. Rep. 40: 1819-1826.

Chen X, Zhang H, McAfee S and Zhang C (2010). The reciprocal relationship between adiponectin and LOX-1 in the regulation of endothelial dysfunction in ApoE knockout mice. Am. J. Physiol. Heart Circ. Physiol. 299: H605-H612.

Cheong MY, Bang OS, Cha MH, Park YK, et al. (2011). Association of the adiponectin gene variations with risk of ischemic stroke in a Korean population. Yonsei Med. J. 52: 20-25.

Chu H, Wang M, Zhong D, Shi D, et al. (2013). AdipoQ polymorphisms are associated with type 2 diabetes mellitus: a meta-analysis study. Diabetes Metab. Res. Rev. 29: 532-545.

Foucan L, Ezourhi N, Maimaitiming S, Hedreville S, et al. (2010). Adiponectin multimersand ADIPOQ T45G in coronary artery disease in Caribbean type 2 diabetic subjects of African descent. Obesity 18: 1466-1468.

Han LY, Wu QH, Jiao ML, Hao YH, et al. (2011). Associations between single-nucleotide polymorphisms ( $+45 \mathrm{~T}>\mathrm{G}$, $+276 \mathrm{G}>\mathrm{T},-11377 \mathrm{C}>\mathrm{G},-11391 \mathrm{G}>\mathrm{A}$ ) of adiponectin gene and type 2 diabetes mellitus: a systematic review and meta-analysis. Diabtologia 54: 2303-2314.

Hegener HH, Lee IM, Cook NR, Ridker PM, et al. (2006). Association of adiponectin gene variations with risk of incident myocardial infarction and ischemic stroke: a nested case-control study. Clin. Chem. 52: 2021-2027.

Jang Y, Lee JH, Chae JS, Kim OY, et al. (2005). Association of the 276G->T polymorphism of the adiponectin gene with cardiovascular disease risk factors in nondiabetic Koreans. Am. J. Clin. Nutr. 82: 760-767.

Jing C, Xueyao H and Linong J (2012). Meta-analysis of association studies between five candidate genes and type 2 diabetes in Chinese Han population. Endocrine 42: 307-320.

Kacso IM, Farcas MF, Pop IV, Bondor CI, et al. (2012). 276G>T polymorphism of the ADIPOQ gene influences plasma adiponectin in type 2 diabetes patients but is not predictive for presence of type 2 diabetes in a Caucasian cohort from Romania. Maedica 7: 271-276.

Kawai T, Ohishi M, Takeya Y, Onishi M, et al. (2013). Adiponectin single nucleotide polymorphism is a genetic risk factor for stroke through high pulse wave pressure: a cohort study. J. Atheroscler. Thromb. 20: 152-160.

Kim SH, Kang ES, Hur KY, Lee HJ, et al. (2008). Adiponectin gene polymorphism $45 \mathrm{~T}>\mathrm{G}$ is associated with carotid artery plaques in patients with type 2 diabetes mellitus. Metabolism 57: 274-279.

Kyriazi E, Tsiotra PC, Boutati E, Ikonomidis I, et al. (2011). Effects of adiponectin in TNF- $\alpha$, IL-6, and IL-10 cytokine 
production from coronary artery disease macrophages. Horm. Metab. Res. 43: 537-544.

Lee KY, Kang HS and Shin YA (2013). Exercise improves adiponectin concentrations irrespective of the adiponectin gene polymorphisms SNP45 and the SNP276 in obese Korean women. Gene 516: 271-276.

Liu F, He Z, Deng S, Zhang H, et al. (2011). Association of adiponectin gene polymorphisms with the risk of ischemic stroke in a Chinese Han population. Mol. Biol. Rep. 38: 1983-1988.

Marousi S, Theodorou G, Karakantza M, Papathanasopoulos P, et al. (2010). Serum adiponectin acutely after an ischemic stroke: implications for a long-lasting, suppressed anti-inflammatory role. Acta Neurol. Scand. 121: 277-284.

Matsumoto M, Ishikawa S and Kajii E (2008). Adiponectin and noncardiovascular death: a nested case-control study. Metabolism 57: 811-818.

Mente A, Meyre D, Lanktree MB, Heydarpour M, et al. (2013). SHARE-AP Investigators. Causal relationship between adiponectin and metabolic traits: a Mendelian randomization study in a multiethnic population. PLoS One 8: e66808.

Motobayashi Y, Izawa-Ishizawa Y, Ishizawa K, Orino S, et al. (2009). Adiponectin inhibits insulin-like growth factor1-induced cell migration by the suppression of extracellular signal-regulated kinase 1/2 activation, but not Akt in vascular smooth muscle cells. Hyperten. Res. 32: 188-193.

Nagasawa H, Yokota C, Toyoda K, Ito A, et al. (2011). High level of plasma adiponectin in acute stroke patients is associated with stroke mortality. J. Neurol. Sci. 304: 102-106.

Ong KL, Li M, Tso AW, Xu A, et al. (2010). Association of genetic variants in the adiponectin gene with adiponectin level and hypertension in Hong Kong Chinese. Eur. J. Endocrinol. 163: 251-257.

Pan W and Kastin AJ (2007). Adipokines and the blood-brain barrier. Peptides 28: 1317-1330.

Pischon T, Pai JK, Manson JE, Hu FB, et al. (2007). Single nucleotide polymorphisms at the adiponectin locus and risk of coronary heart disease in men and women. Obesity 15: 2051-2060.

Rabe K, Lehrke M, Parhofer KG and Broedl UC (2008). Adipokines and insulin resistance. Mol. Med. 14: 741-751.

Walsh K (2009). Adipokines, myokines and cardiovascular disease. Circ. J. 73: 13-18.

Wasim H, Al-Daghri NM, Chetty R, McTernan PG, et al. (2006). Relationship of serum adiponectin and resistin to glucose intolerance and fat topography in South-Asians. Cardiovasc. Diabetol. 5: 10.

Yamada Y, Kato K, Oguri M, Yoshida T, et al. (2008). Association of genetic variants with atherothrombotic cerebral infarction in Japanese individuals with metabolic syndrome. Int. J. Mol. Med. 21: 801-808.

Yatomi K, Miyamoto N, Komine-Kobayashi M, Liu M, et al. (2009). Pathophysiological dual action of adiponectin after transient focal ischemia in mouse brain. Brain Res. 1297: 169-176. 